\title{
Análisis de la producción y del comercio de maquinaria agrícola argentina en la competencia regional (2002-2014)
}

\section{Analysis of the production and trade of Argentine agricultural machinery in the regional competition (2002-2014)}

\author{
Damian Andrés Bil \\ Investigador asistente CEUR - CONICET \\ http://orcid.org/0000-0002-7054-2927 \\ damianbil@conicet.gov.ar, damibil@gmail.com
}

Fecha de recepción: 08 de marzo de 2016

Fecha de aceptación: 18 de noviembre de 2016

Sugerencia de citación: Bil, D.A. (2017). Análisis de la producción y del comercio de maquinaria agrícola argentina en la competencia regional (2002-2014).

tiempo\&economía, 4(1), 101-124,

doi: http://dx.doi.org/10.21789/24222704.1186

\section{RESUMEN}

Durante la última década, el sector de maquinaria agrícola fue señalado como puntal de un aparente nuevo modelo productivo. Este escenario estaba motivado por nuevos emprendimientos y el crecimiento en las exportaciones de ciertos productos de la rama, a mercados como Venezuela y Rusia, entre otros. No obstante, la crisis de 2014 desnudó los inconvenientes de la actividad.

En ese sentido, reconstruimos los indicadores generales del mercado de maquinaria agrícola y de su mercado externo, sin obviar la perspectiva histórica, para comprender los factores 
que permitieron su desarrollo y también los que lo limitaron. El objetivo es aportar a la comprensión de los límites exportadores de la industria argentina. Buscamos comprender si los problemas actuales responden a una situación coyuntural o pasajera; o bien, si representan límites estructurales de este tipo de producción.

Palabras clave: industria, maquinaria agrícola, exportación, Argentina

Códigos JEL: L64, N60

\section{ABSTRACT}

Over the past decade, the Argentine agricultural machinery industry was shown as an example of an apparent new productive model. This scenario was motivated by the emergence of new enterprises and the growth in the exports of certain machines to different countries (Venezuela, Russia and others). However, the crisis of 2014 showed the problems of the activity.

In that sense, we reconstruct the general market indicators and its external market, without ignoring the historical perspective to understand the factors that allowed their development and also the limits. The objective is to contribute to understand the exports limits of the Argentine industry. We seek to understand whether current problems respond to a short-term or temporary situation; or if they represent structural limits of this type of production.

Keywords: Industry, Agricultural Machinery, Exports, Argentina

JEL Codes: L64, N60 


\section{Introducción}

Durante los últimos años, la situación del sector de maquinaria agrícola argentino, con el crecimiento de clústeres regionales y de nuevas empresas fabricantes nacionales y extranjeras (Langard, 2014a), habilitó un panorama de euforia acerca del futuro de esta actividad "no tradicional". Tanto la devaluación post 2001 como los precios agrarios internacionales en alza, provocaron un repunte de la actividad en relación a la década previa. Entre 2002 y 2007, las ventas aumentaron considerablemente. Varios fabricantes se reposicionaron, favorecidos por una reducción del costo laboral. Con este movimiento, resurgieron las esperanzas de desarroIlo nacional por medio de la vía PyME, reflejado en el caso de la expansión de pequeñas empresas en localidades agroindustriales, como es el caso de Las Parejas en la provincia de Santa Fe (Moltoni, 2009; Gorenstein y Moltoni, 2011; Arteche, Santucci et al., 2013). La expresidenta Cristina Fernández llegó incluso a promocionar, junto al gobernador de Entre Ríos, la fabricación de una cosechadora íntegramente nacional en 2012 (Clarín, 2014). En ese movimiento, se logró exportar ciertos productos a mercados como Rusia, Venezuela, Colombia, Ecuador, Chile, Paraguay y otros países de Sudamérica. Parecía que Argentina iba a contar con una rama no tradicional que lograría insertarse favorablemente en el mercado mundial. El aumento de la facturación era anunciado como indicio indiscutible del despegue de la actividad; lo que se reflejó durante la primera década del siglo en medios periodísticos y académicos.

No obstante, aun antes de la crisis del campo de 2008, ciertos indicadores comenzaron a mostrar fisuras. En términos absolutos, en 2007 se alcanzó el punto máximo de ventas en el mercado interno (con 28.028 unidades entre cosechadoras, tractores, sembradoras y pulverizadoras), y a partir de ahí las ventas entraron en retroceso. El ciclo ascendente que mostraban desde 2002 se estancó. Desde el mismo sector se escucharon las voces de alarma. ${ }^{1}$ En 2009 las ventas se desplomaron, aun por detrás de los niveles de 2002. Si bien luego de la crisis la demanda se recuperó parcialmente, nunca alcanzó los niveles de 2008 o incluso de los años anteriores. Más aun, en 2014 las ventas en unidades fueron un 4\% menores que las de 2009, en plena crisis (INDEC, 2015).

Consideramos que este fenómeno expresa los límites del sector en Argentina, que no son novedosos, sino que tienen raíces históricas. Uno de esos problemas se encuentra en la poca capacidad competitiva de la producción argentina en el mercado mundial (puede verse un análisis con puntos en común en Pellegrini, 2005).

En este artículo, reseñamos la evolución del sector de mayor peso en la rama: la producción de cosechadoras, tractores y sembradoras. Nos concentramos en este sector porque es la producción de mayor valor y equipos más complejos y a nivel mundial representa más del $80 \%$ del comercio mundial del capítulo. Vale mencionar que en la Argentina existe, además, un sector de fabricantes de sembradoras (particularmente de siembra directa) e implementos que proveen al mercado interno. Incluso, Argentina exporta algunas sembradoras a Venezuela, Uruguay, Rusia, Bolivia y, en menor medida, a otros países. Analizaremos el fenómeno y el peso de esas exportaciones a nivel mundial.

1 Puede verse artículos como “Fuerte preocupación en las empresas de maquinaria agrícola” (La Nación, 2008); "Alertan por avalancha brasileña y exigen apoyo" (Infobae, 2008); "Los fierros ajustan las tuercas" (Clarín Rural, 2008); "Maquinaria agrícola: vacaciones hasta febrero para evitar despidos" (Infocampo, 2008).

tiempo\&economía Vol. 4 N. ${ }^{\circ} 1$ - I semestre de 2017 
En primer lugar repasamos la historia del sector para analizar sus limitaciones históricas. Luego abordamos la dinámica actual del mercado mundial para entender cómo se actualizan esos problemas. Para profundizar en esa perspectiva, estudiamos el lugar de Brasil, líder regional en el sector. De esta manera, esperamos aportar conocimiento para un análisis de las perspectivas de la actividad. El trabajo puede ser útil como contribución a los debates sobre el desarrollo de la industria en Argentina y su potencialidad exportadora en este sector específico.

\section{Origen y desarrollo de la fabricación de cosechadoras y tractores en Argentina}

El repaso por los orígenes del sector nos permite encontrar rasgos que limitaron una expansión mayor. La fabricación de implementos agrícolas se inició con los orígenes de la producción cerealera. Hacia fines del siglo XIX, Argentina era uno de los principales exportadores de cereales. Desde la década de 1860, comenzaron a instalarse los primeros fabricantes de implementos (arados, rastras, accesorios para trilladoras, entre otras), en las localidades agrícolas de la provincia de Santa Fe. La producción de maquinaria fue más tardía. A fines de la década de 1910 se inició esta actividad en el país, también en Santa Fe, más allá de algunas efímeras iniciativas previas. Talleres de reparación comenzaron a reformar equipos importados. Luego se dedicaron a la fabricación. Entre los que instalaron su pequeño taller de campaña y luego se dedicaron a la producción se encontraban los hermanos Juan y Emilio Senor (de San Vicente). En 1921 instalaba la que sería la primera planta de armado de cosechadoras en Sudamérica. Entre otros pioneros de la provincia de Santa Fe, como Luis Gnero (Colonia Susana), Santiago Puzzi (Clucellas), Andrés Bernardín (San Vicente); se ubicó Alfredo Rotania, que instaló un taller en Sunchales, en 1915. Durante años se dedicó a la producción de accesorios para las máquinas. En 1927 consideró necesario aprovechar en el mismo módulo la trilladora, la segadora y el tractor. Inició entonces la construcción de un prototipo. En 1929 salía a la venta la "espigadora-trilladora, con adaptabilidad de un tren automotriz en el rodado delantero". Es decir, la primera cosechadora automotriz del mundo (Bil, 2009).

Durante la "crisis del treinta", ante el descenso de importaciones, los fabricantes tuvieron dificultades en el aprovisionamiento de insumos. Muchos debieron recurrir a otras fuentes de aprovisionamiento; como el desguace de automóviles o tractores en desuso. Luego de los primeros años de la crisis, al reestablecerse las importaciones, la producción aumentó. Según el censo de 1937, se habían producido ese año 495 cosechadoras. Un año más tarde, la firma Senor fabricaba más de 200 cosechadoras automotrices anuales, con una venta acumulada de 1.150 unidades desde 1921 (Catálogo Senor, 1940).

Producto de la suspensión de importaciones ocasionada por la Segunda Guerra, de la obsolescencia de gran parte del parque y de la falta de divisas para importar equipos desde la crisis de 1949, se decidió impulsar la fabricación local. Primero se brindaron facilidades crediticias para fabricantes, luego se expidieron permisos de importación y, finalmente, se declaró "de interés nacional" la industria en 1951. Se retiró a las cosechadoras de las listas del régimen de permisos de cambio ubicándolas fuera de norma, impidiendo su importación (AFAC, 1972). Surgió una segunda camada de fabricantes: Vassalli (Firmat), GEMA (Rosario) y Giubergia (Venado Tuerto) entre los más importantes y también se constituyó la industria auxiliar. 
La industria de tractores surgió en los primeros años de la década de 1950. Por decreto, en agosto de 1952, se creó la primera fábrica: se autorizó a las Industrias Aeronáuticas y Mecánicas del Estado (IAME) "a construir por sí y en cooperación con las industrias privadas, tractores íntegramente nacionales". Se empezaron a producir en 1953 con asistencia de Fiat. Comenzó con el modelo Pampa, basado en el antiguo Lanz Bulldog alemán de 1930 (Proyección Rural, 1969). En 1954 se convocó a licitación internacional, en la cual se aceptaron las propuestas de Deutz, Fahr, Hanomag y Fiat. En 1957 se sancionó el decreto ley 15.385, por el cual se declaró de interés nacional la producción específica de tractores. Se establecía un mínimo de un $40 \%$ de valor nacional en cada unidad, que iría en progresivo aumento. También se establecían primas a la producción y se eximía del impuesto a las ventas a los tractores nacionales. En 1959 se instaló John Deere en Granadero Baigorria, Santa Fe.

Entre las décadas del sesenta y el setenta, las firmas locales de cosechadoras y tractores se consolidaron en el mercado interno. Por caso, Senor fabricó, en 1960, 450 cosechadoras automotrices de sus dos principales modelos, 130 plataformas maiceras, 100 equipos girasoleros, 300 recolectores y varios accesorios. La empresa más importante, Vassalli, contaba en 1973 con 400 obreros, fabricaba 500 cosechadoras anuales y 350 equipos maiceros. Hacia comienzos de la década de 1970 un informe de AFAC registraba 17 fábricas de cosechadoras, cuya capacidad anual era de 3.200 unidades, aunque operaban al 35\% de capacidad.

Desde mediados de los 60, y durante aproximadamente una década, el sector exportó a otros países de Sud y Centroamérica (Bil, 2013) a razón de 1.350 cosechadoras entre 1967 y 1971. Pero en esos mercados la competencia de las firmas líderes se hacía sentir por diversos medios. Las filiales de los capitales líderes podían vender a plazos de diez años. Ese era un procedimiento que los capitales argentinos no podían afrontar por su menor escala. Hay que tener en cuenta que, para ese momento, las fábricas argentinas producían menos de 1.000 unidades cada una: 23 plantas llegaban solamente a 2.500 unidades anuales, con costos de insumos entre $40 \%$ y $100 \%$ superiores a los de Europa (Dziecielewski, 1973). Las plantas más grandes a nivel mundial producían entre 5.000 y 20.000 unidades cada una, por lo que los fabricantes locales percibían los problemas. Como confesaba la Cámara, mercados "prometedores", como Brasil y México, montaron su propia industria que logró abastecer sus respectivos mercados (Proyección Rural, 1969). Entre 1960 y 1976, Brasil instaló primero su estructura productiva del sector tractores y, luego, la de cosechadoras. En México, entre 1963 y 1965, se instalaron John Deere, International Harvester, Massey Ferguson y Ford (Pérez Ojeda, 1970). Según la Secretaría de Industria, el costo de la producción argentina en tractores era un 40\% superior al de Brasil y México. La escala era reducida: aun en sus mejores años, a mediados de los setenta, la producción argentina de tractores y cosechadoras difícilmente alcanzaba el 1\% de la producción mundial. Estos elementos dificultaban la inserción argentina en el mercado exterior.

\section{Producción y mercado desde la apertura a la actualidad}

La mayor parte de los análisis de historia económica argentina insisten en que a partir de mediados de la década de 1970, con la apertura de la economía, se abrió un nuevo patrón de

tiempo\&economía

Vol. 4 N. ${ }^{\circ} 1$ - I semestre de 2017 
acumulación vinculado a las finanzas y a la desindustrialización. ${ }^{2}$ Si bien se produjeron cambios en la estructura económica e industrial en el país, esta corriente omite entre otros elementos el análisis del mercado mundial, lo que impide comprender el fenómeno en su conjunto. Reincorporamos este factor con el fin de entender cuál es el desempeño específico de la actividad.

En los años ochenta, la crisis mundial repercutió sobre el sector, con quiebras de grandes compañías, fusiones y formación de consorcios. En el plano local, sería un momento de estancamiento de la actividad, con el cierre de firmas (Langard, 2014b). A partir de la segunda mitad de la década, se produce el franco descenso de la producción. Durante los años noventa, la producción local es ostensiblemente menor a las previas, especialmente en cosechadoras. Con los datos disponibles de la serie, la producción promedio cayó de 1.079 unidades anuales para la década de 1980, a 548 para la de 1990. Es decir, un 49\%. En cuanto a tractores, el promedio bajó de 5.744 unidades anuales de los años ochenta a las 3.880 de la década siguiente; un $32 \%$. Estas cifras evidencian algo que suele pasarse por alto: los resultados de la década de 2000 y 2010 no son mejores que los de las anteriores. En tractores, el promedio se ubicó en 915 y 1.926; mientras que en cosechadoras en torno a 445 para la primera década del siglo (INDEC, 2016) y 273 para el periodo 2010-2014 (CAFMA, 2016). Es decir, los promedios de las décadas signadas por la apertura y la denominada "desindustrialización" tienen una performance superior en comparación a los últimos quince años. Es cierto que parte del descenso puede explicarse por la aparición de unidades de mayor potencia en 30 años; pero esto no da cuenta de la drástica caída en la fabricación.

Gráfico 1a y 1b. Producción de tractores y cosechadoras en Argentina (1985-2014) unidades
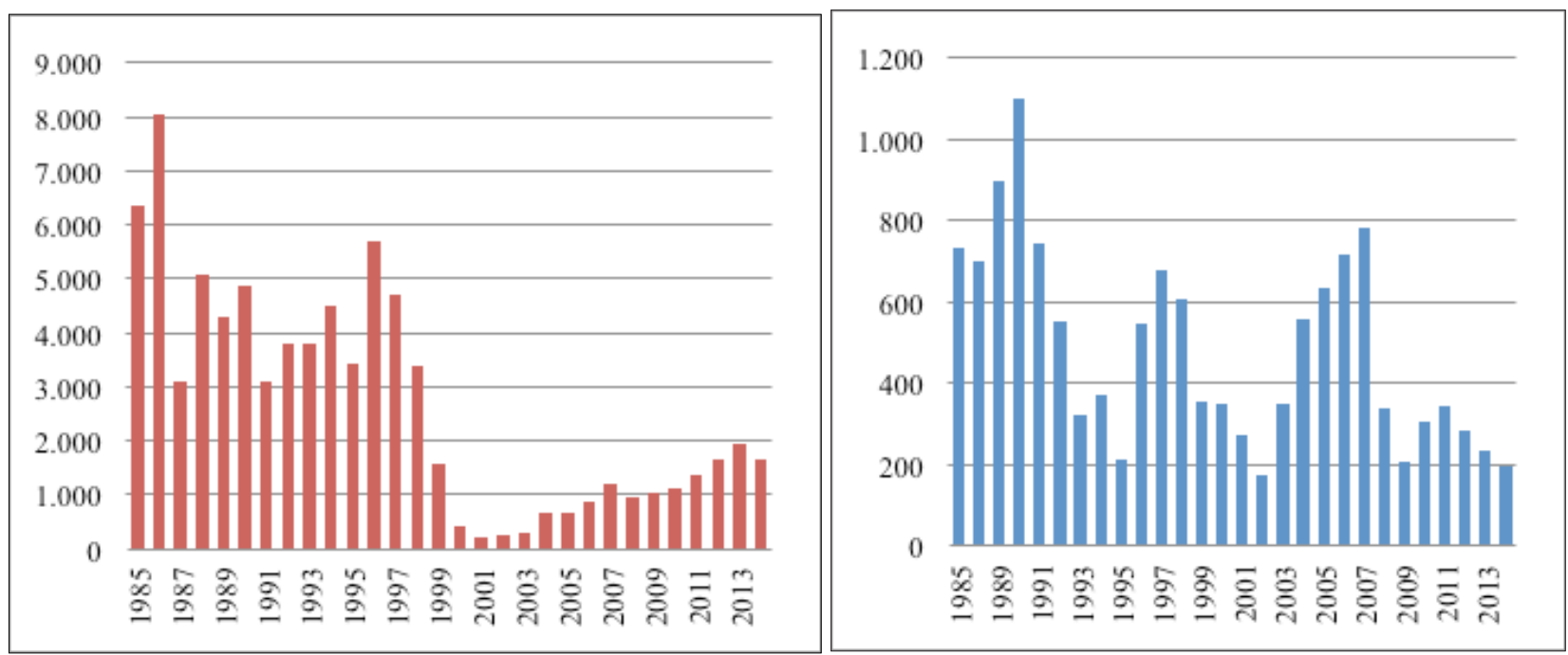

Nota: 1987 y 1988 sin datos disponibles de cosechadoras.

Fuente: elaboración propia con base en datos de CAFMA, INDEC, AFAT y Langard (2014).

Como se observa en el Gráfico 1, el nivel de la caída entre la última década del siglo XX y las décadas de 2000 y 2010 es considerable. Pero esto no se debe tanto a una retracción en el mer-

2 Hemos discutido la periodización en modelos en Bil et al. (2010). Otros autores que discuten esta concepción son, entre otros, Sartelli (2006) e Iñigo Carrera (1998). 
cado, sino a la reducida competitividad del sector. Por el contrario, las ventas se incrementaron (Gráfico 2).

Gráfico 2a y 2b: producción y venta de tractores y cosechadoras (1980-2014) en unidades

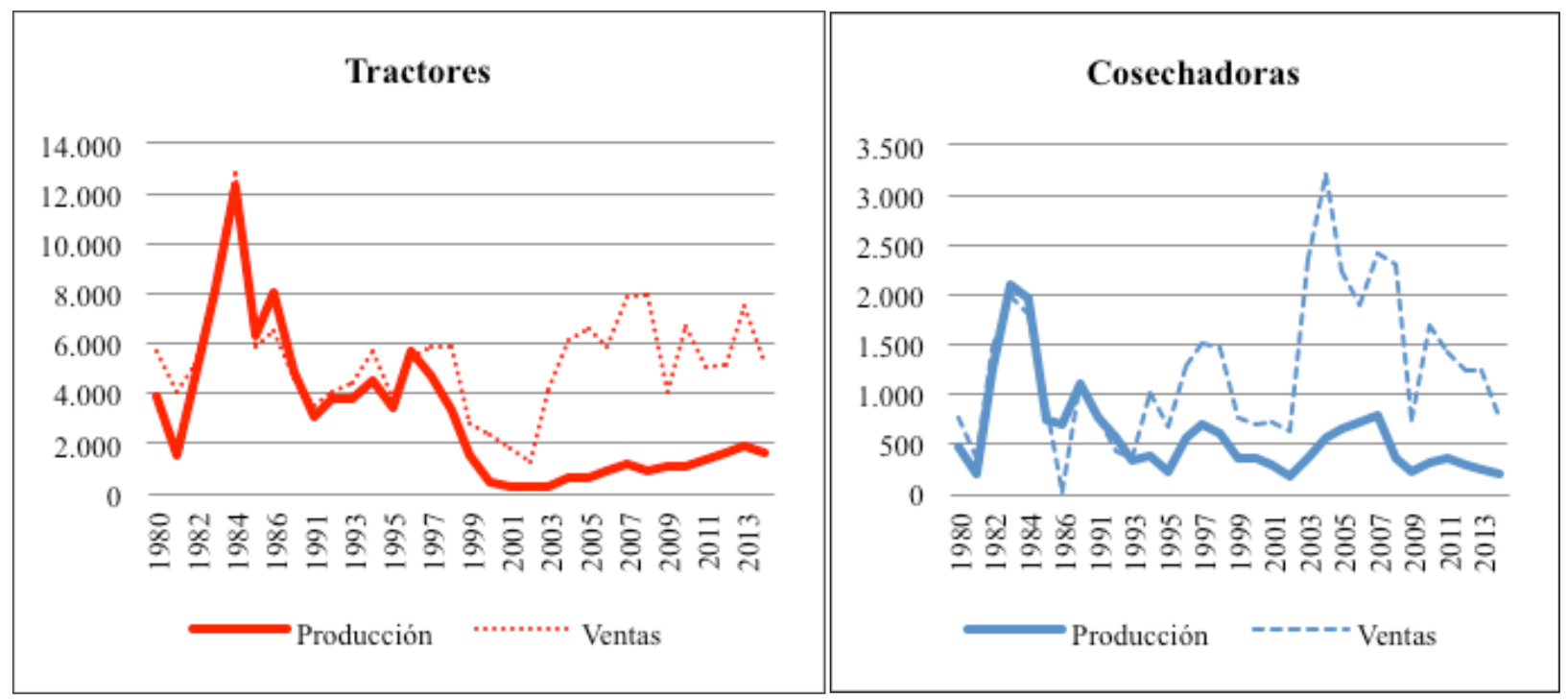

Nota: por carencia de datos, no se computan en la serie los años comprendidos entre 1986 y 1989. Fuente: elaboración propia con base en datos de CAFMA, INDEC, AFAT y Langard (2014).

Desde 2002 se produce una grieta entre la demanda y la producción local. Esa demanda se cubre, en su mayor parte, por importados en buena medida provenientes de Brasil. En el Gráfico 3 se observa como durante la última década en ventas internas de cosechadoras y tractores, los equipos con mayor valor agregado dominan los importados (un $70 \%$ de las unidades vendidas), hasta que las restricciones a la importación que aparecen en torno a 2012 disminuyen su peso.

Gráfico 3a y 3b. Venta de tractores y cosechadoras por origen de la unidad (2004-2014)
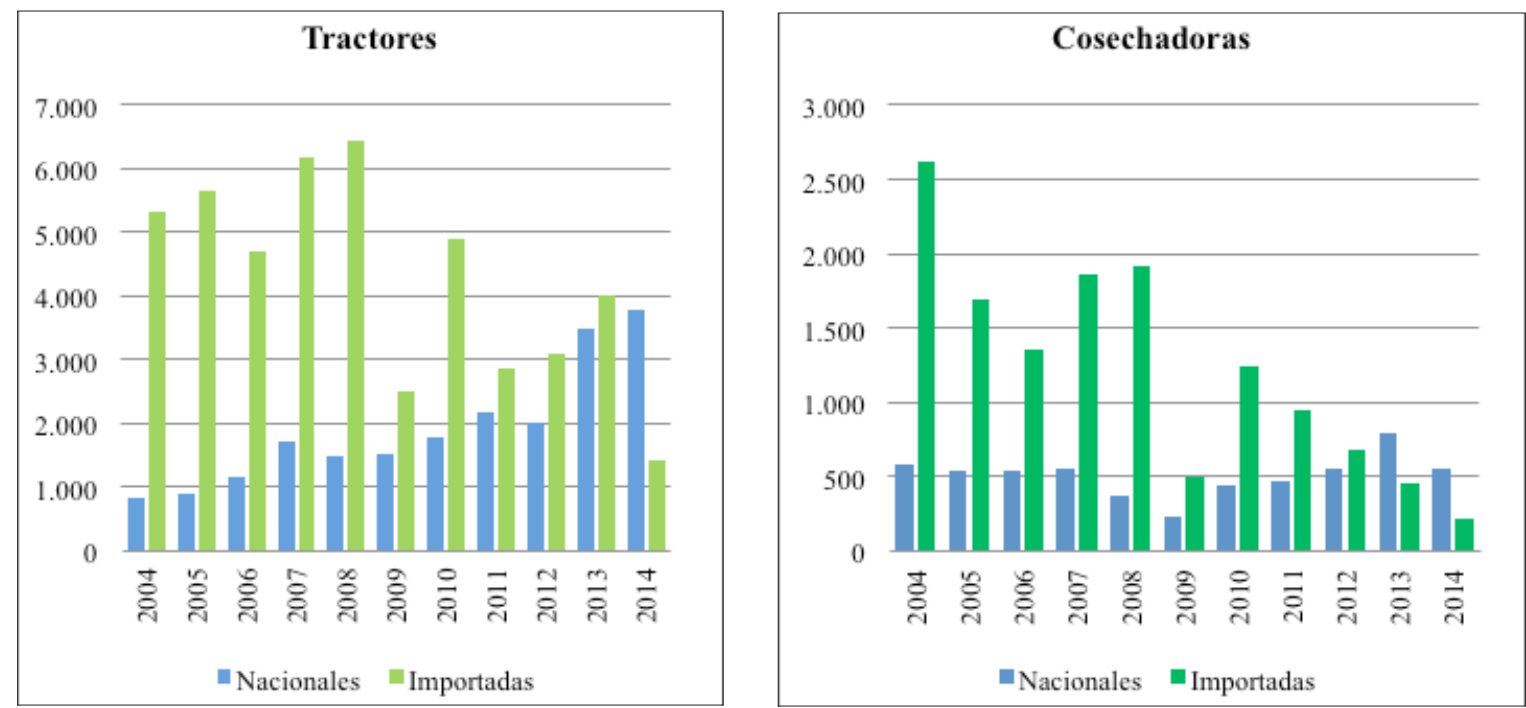

Fuente: elaboración propia con base en INDEC (2015). 
En la facturación se observa un movimiento similar, e incluso se evidencia el estancamiento del mercado interno luego de la crisis de 2009, con relación a la primera mitad de la década

Gráfico 4. Valor de ventas de cosechadoras, tractores, sembradoras e implementos por origen de unidad vendida (2004-2014) en millones de pesos de 2015

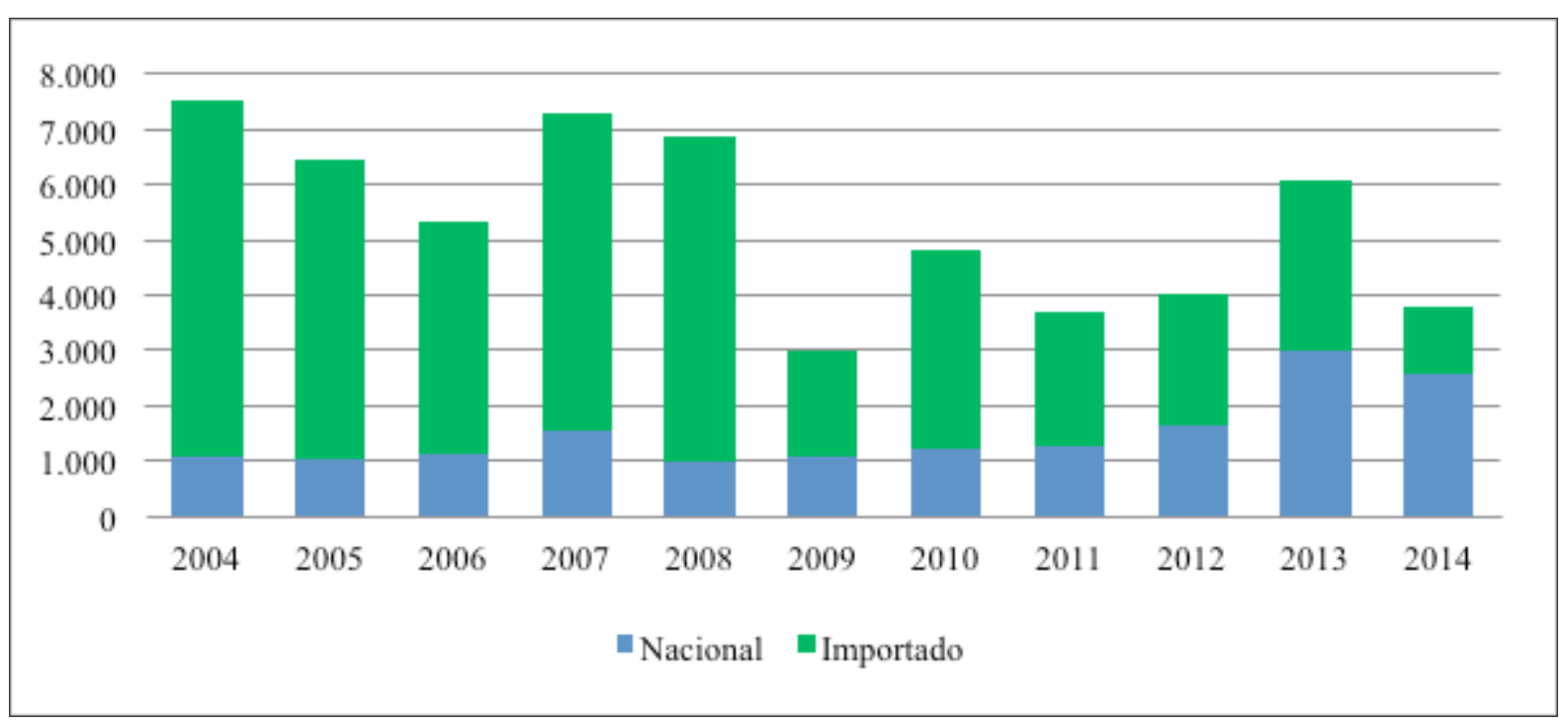

Fuente: elaboración propia con base en INDEC (2015).

En este gráfico volcamos la facturación general del sector, pero cabe señalar que en sembradoras, la participación de la fabricación nacional en el mercado es del 99\%. Los analistas que estudiaron la actividad, aun con diferencias entre sí, enumeran una serie de motivos para explicar el peso de la participación nacional. Uno de ellos sería la diversidad de cultivos y la extensa superficie de producción que provocan diversa necesidad de abastecimiento, lo que habilitó el surgimiento de firmas de series cortas (Baruj, 2005; AACREA, 2005). Para Bragachini (2006), del INTA, este fenómeno se explicaría por la existencia de nichos de mercado muy particulares, que resultan en demandas acotadas (en muchos casos sin llegar a quince unidades por modelo) y que configuran un sector con baja escala y diseño muy plástico. Otros discuten esta perspectiva señalando que la ventaja se encontraría en la rápida adopción de la siembra directa en relación con el resto del mundo, que permitió a los fabricantes locales acaparar ese mercado (Albornoz et al., 2010). Por su parte, García (2005) atribuye la capacidad de los fabricantes de sembradoras de proveer al mercado interno de cambios tecnológicos y de procesos introducidos en la década de los noventa, que le otorgarían a la actividad una gran flexibilidad productiva, en primer lugar, y en segundo término a la estrategia de las empresas de tercerización de compras para bajar costos. El proceso de tareas simples y flexibles no implicaría grandes inversiones en capital fijo, lo que, sumado a los elementos anteriores, posibilitaría la oferta de un producto de cierta calidad y más accesible que los importados. ${ }^{3}$

3 Como se desprende de la enumeración de posibles motivos, existen diversas interpretaciones para explicar el peso de la producción nacional de sembradoras. No contamos con el espacio aquí para profundizar en ese análisis, por lo que será tema para futuros trabajos. 
En relación al peso de las importaciones en el conjunto de la rama, lo que encontramos es que la fabricación de cosechadoras y tractores en Argentina parece estar en peores condiciones que en los setenta, puesto que ni siquiera domina el mercado interno. Además de la caída en el volumen de producción, el peso de los importados en la última década fue determinante. Esto indica un problema en la competitividad de la industria.

La situación en otros equipos e implementos específicos, como las sembradoras, contribuyen a equilibrar en cierta medida la balanza entre las ventas de unidades nacionales e importadas, pero no cambian la tendencia señalada. A su vez, en el saldo de la balanza comercial la actividad muestra déficit.

Consideramos que para comprender mejor los motivos de esa situación y de los límites competitivos de la actividad, debemos observar cómo funciona el mercado mundial y cómo se inserta Argentina en el mismo.

\section{Estructura y dinámica actual del mercado mundial de cosechadoras y tractores}

La característica más evidente del mercado mundial es su concentración. Está dominado por seis consorcios económicos que reúnen varias firmas líderes. En las últimas décadas se ha dado un proceso de centralización, por el cual varias empresas fueron absorbidas por consorcios del ramo. El más grande es el grupo John Deere, que en 2014 facturó solo en su división agrícola 26.380 millones de dólares (Deere \& Company, 2015). El grupo CNH ocupa el segundo lugar. Su historia se remonta a 1985, cuando Ford adquirió la firma de implementos New Holland. En 1991, Ford-New Holland-Versatile vendió el $80 \%$ de su paquete accionario a Fiat de Turín. En 1994, el 20\% restante fue comprado por Fiat-Geotech, subsidiaria de Fiat Turín. Finalmente, en 1999 New Holland adquirió la centenaria firma Case, líder en producción de tractores y cosechadoras, y uno de los capitales más grandes de Estados Unidos. A partir de ese momento, se constituyó como $\mathrm{CNH} .{ }^{4}$ Para 2009 tenía 12.000 concesionarios en 160 países y cuenta con plantas, centros de desarrollo y joint ventures en otros doce.

El tercer grupo en importancia es AGCO, norteamericano, que inició operaciones con la compra del grupo Deutz-Allis en 1990. En 2004 adquirió Valtra y la fábrica finlandesa de motores diesel Kone. Opera en más de 140 países, principalmente en Estados Unidos y Latinoamérica, con trece marcas registradas, entre las cuales se encuentran Massey Ferguson, Fendt, Allis, Gleaner y Deutz.

La cuarta firma es Claas, de origen alemán. Tiene diez plantas, cinco de ellas en Alemania. Creció a partir de la adquisición de firmas pequeñas, hasta que en 2003 realizó la primera compra de magnitud al adquirir la mayoría del paquete accionario de Renault Agriculture, que pasó a convertirse en su división de tractores. Cuenta con una nómina de 11.000 obreros en el mundo, un $70 \%$ fuera de Alemania.

4 A su vez, Case había sido adquirido anteriormente por Tenneco Inc., la mayor distribuidora de gas del mundo tiempo\&economía Vol. 4 N. ${ }^{\circ} 1$ - I semestre de 2017 
SAME Deutz-Fahr es un consorcio que reúne a Same, Deutz, Fahr, Lamborghini y la suiza Hürlimann. Es uno de los principales fabricantes de tractores del mundo. Con colaboración del Deutsche Bank y de Volvo, accedió a un paquete mayoritario del grupo Deutz AG, líder en fabricación de motores diesel y a gas. Sus principales plantas de tractores se encuentran en Treviglio (Italia), Lauingen (Alemania), Lublin (Polonia) y Ranipet (India). En 2004 fabricaron más de 32.000 unidades. Por último, ARGO SpA es una corporación italiana que reúne varias firmas como Landini, McCormick, Valpadana, Laverda, Sep y Pegoraro.

En 2005, el valor de la producción mundial alcanzó los sesenta mil millones de dólares: John Deere representó un 23\%, mientras la CNH la siguió con 20\%. AGCO representó un 5\%, DeutzFahr y Claas un $2 \%$ cada una. El resto de los fabricantes mundiales acapararon el $48 \%$ restante (de Cet, 2006; Hybel, 2006; Donoso, 2007). La magnitud de estos grupos da una imagen de los tamaños de los capitales que se disputan los mercados y los límites de escala que mantiene Argentina en términos históricos. Por ejemplo, mientras que en 2010 Argentina produjo 5.050 sembradoras, en Estados Unidos se fabricaron 82.155 (US Census, 2010), y en 2013, mientras aquí se despacharon de fábrica 235 cosechadoras y 1.947 tractores, en Brasil se hacían 9.948 y 77.570, respectivamente, (ANFAVEA, 2016) y en Japón 24.403 y 152.962, respectivamente, (JAMMA, 2014).

Las estrategias de estos grupos es producir en las diferentes regiones, de forma directa o por joint ventures con locales, acaparando mercados específicos. En Sudamérica, la demanda está provista principalmente por Brasil y Estados Unidos. En Argentina, mantienen filiales de venta o asociaciones con locales, como Same-Deutz con Mainero, Agco con Massey Ferguson de Argentina o importando las cosechadoras como Gleaner de EE. UU. y MF de Brasil.

En cuanto al mercado mundial, si tomamos el movimiento de tractores, cosechadoras y sembradoras (o sea, los productos que explican más de dos tercios del comercio del rubro), los mayores importadores son las economías más poderosas y los países con un sector agrario de peso. En valores constantes, en el periodo 2002-2011 EE. UU. absorbió casi un 15\% de las compras mundiales, seguido por Australia (8,5\%), Alemania (7,5\%), Ucrania $(5,2 \%)$ y Canadá $(5 \%)$. Argentina, a pesar de ser uno de los mayores importadores de cosechadoras, solo representa el $0,7 \%$ de las importaciones mundiales.

Estos mercados concentran casi el $60 \%$ de las importaciones mundiales en esos años. Es interesante señalar que, a pesar de tener un sector fabricante local, en 2007 y 2008 Argentina se posicionó como segundo importador mundial (con 240 millones de dólares en compras anuales), detrás de Canadá. No obstante, a pesar de tener un mercado doméstico con cierta magnitud y fabricantes de distintos implementos, no es un exportador de peso, como puede verse en el gráfico 6.

La producción de seis países domina el 70 \% del mercado mundial. Estos se encuentran alejados del resto. En segundo lugar, al menos cinco de los principales importadores también son líderes en exportación de tractores y cosechadoras. Por último, es pertinente destacar que Brasil, si bien ocupa el séptimo lugar en el orden de los exportadores, no tiene una participación mayoritaria en el mercado mundial, apenas supera el 3\% y básicamente su influencia está en el mercado latinoamericano, que no es el más dinámico. En proporción, se encuentra lejos de Alemania, Estados Unidos e Italia, que logran entrar en diversas plazas. 
Argentina tiene una escasa capacidad competitiva en mercados externos. En relación a Brasil, el competidor más cercano, tiene una participación 20 veces menor, con solo $0,2 \%$ y en el comercio de cosechadoras apenas tiene un 0,5\% del valor comercializado a nivel mundial, gracias a las compras de Venezuela, el mayor destino de la fabricación local. En efecto, la producción argentina se dirige a mercados secundarios en el plano mundial (gráfico 7).

Gráfico 5. importación de cosechadoras, sembradoras y tractores en porcentaje del total del movimiento mundial (2002-2011) en países seleccionados

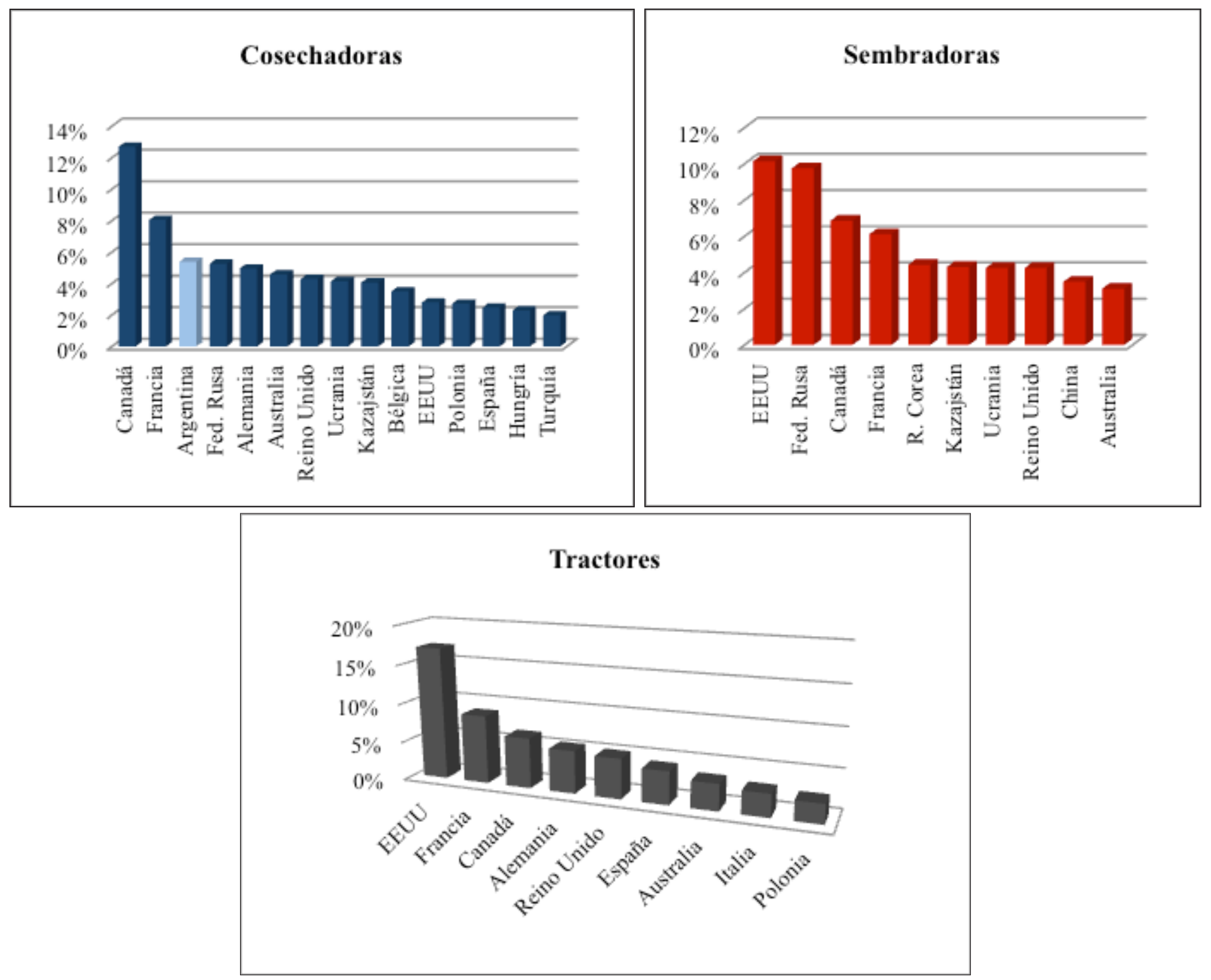

Fuente: elaboración propia con base en datos de UNComtrade. 
Gráfico 6. exportación de cosechadoras, sembradoras y tractores en porcentaje del total del movimiento mundial (2002-2011) en países seleccionados
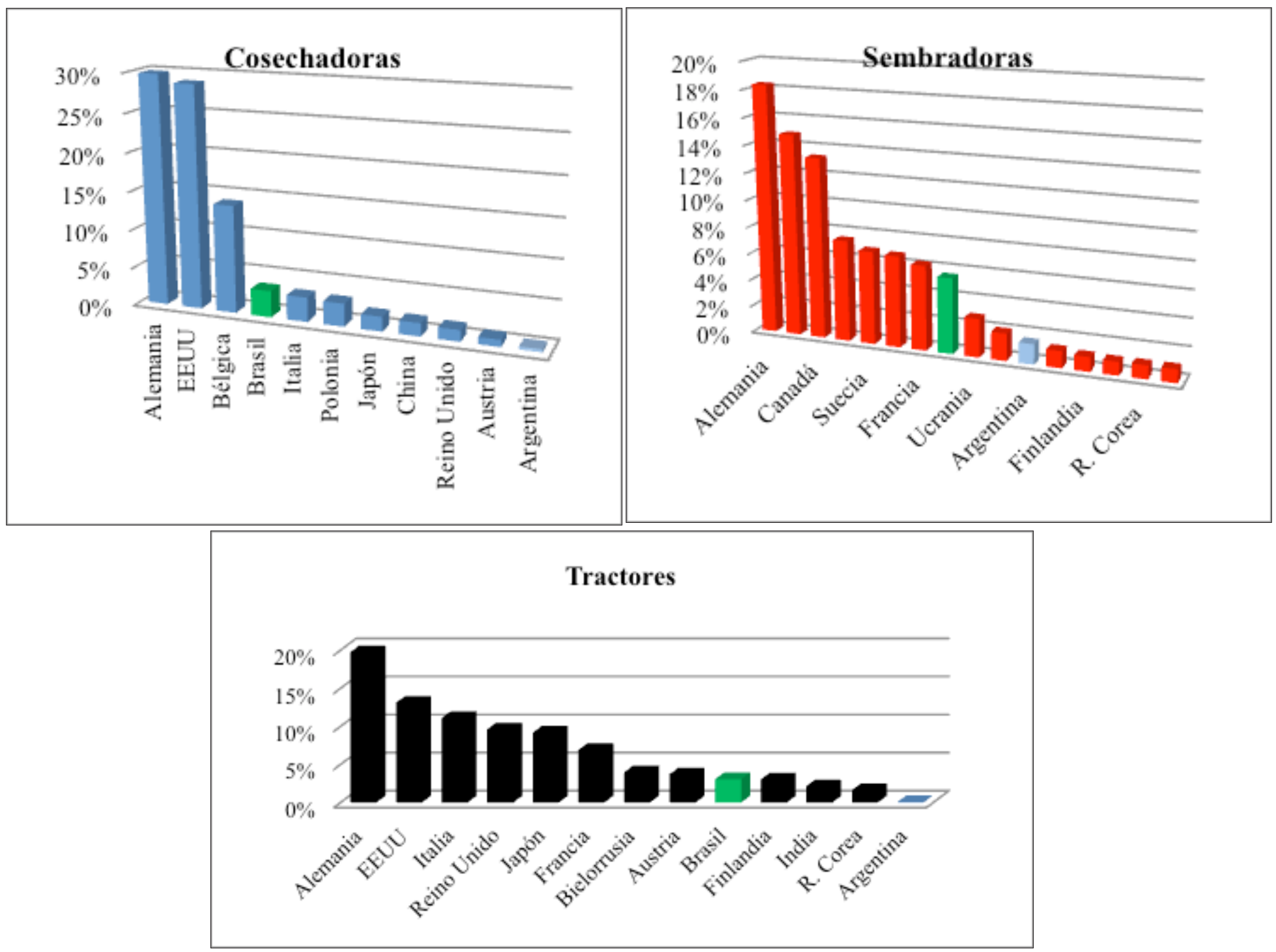

Nota: tractores hasta 2014

Fuente: elaboración propia con base en datos de UNComtrade.

A pesar del incremento de las exportaciones a Venezuela y de la cercanía con Uruguay y Bolivia, Argentina no domina ninguno de estos mercados. Brasil, México y Bielorrusia concentraron el $70 \%$ de las ventas al país caribeño. Tanto en Bolivia como en Uruguay, los productos argentinos están lejos de los brasileños y norteamericanos. El resto de los mercados de Latinoamérica también están cubiertos por estos proveedores. Los problemas de competitividad se expresan no solo en las dificultades para ganar mercados, sino en el saldo comercial deficitario de la actividad (Gráfico 8): 
Gráfico 7. principales mercados de Argentina en cosechadoras, sembradoras y tractores. Porcentaje del total acumulado entre 2002 y 2011

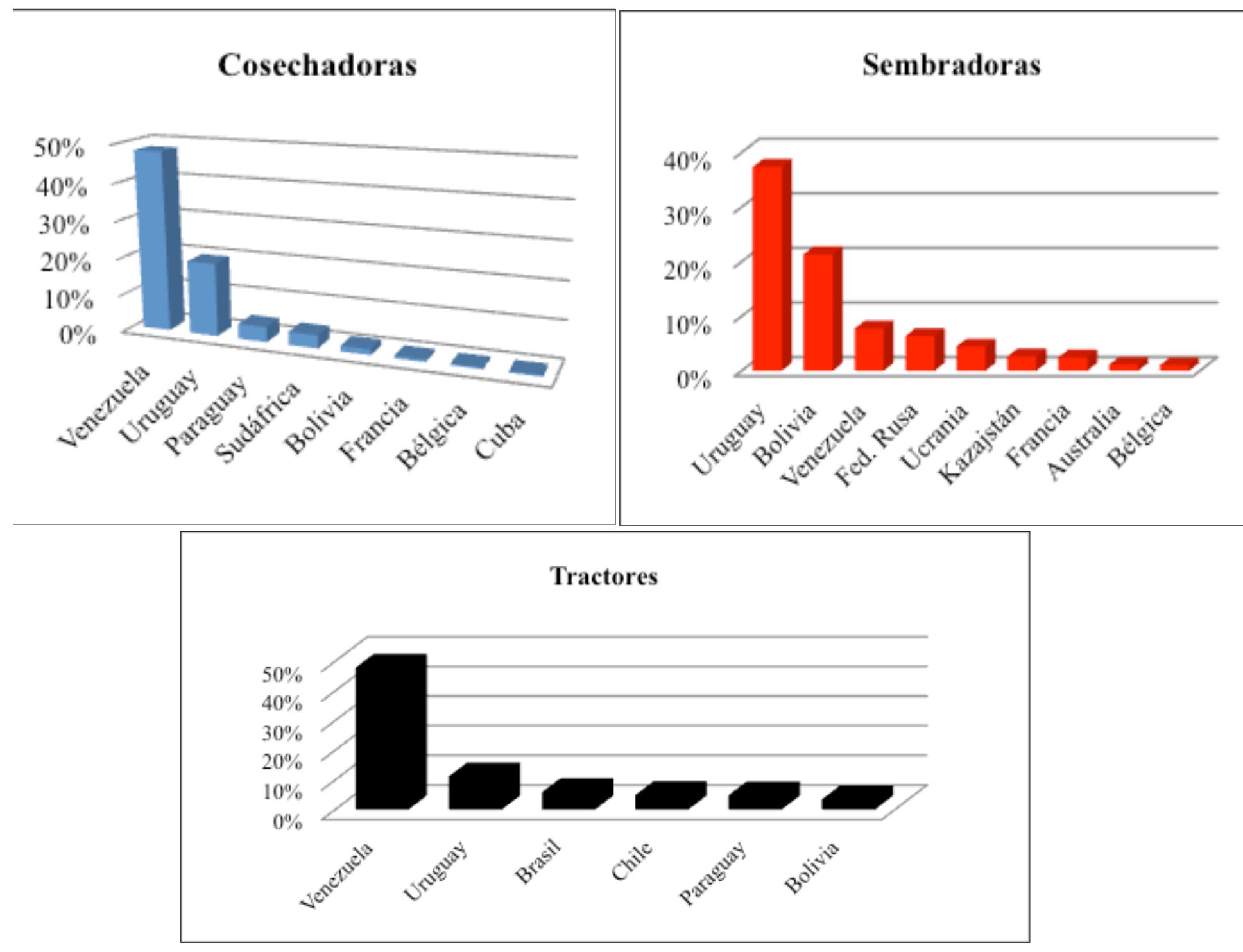

Fuente: elaboración propia con base en datos de UnComtrade.

El saldo comercial es negativo durante los últimos años. Tractores y cosechadoras son deficitarios, mientras que sembradoras tiene un pequeño superávit. Entre 2012 y 2014 el déficit comercial tendió a reducirse, pero no por una mejoría en las exportaciones, sino por la brusca caída de las importaciones de equipos vinculada a los problemas de divisas y económicos generales.

Vale una breve mención en el caso de sembradoras, que se ha señalado como sector con potencialidad exportadora: si bien es cierto que la rama expandió sus exportaciones y llegó a diversos mercados, a nivel mundial su participación es menor. Argentina es el noveno exportador mundial del rubro, con una participación en su mejor momento (2007-2011) del 2,1\%, con 25 millones de dólares anuales. Lejos de los más dinámicos (Estados Unidos, Alemania, Canadá y Japón). 
Gráfico 8. saldo comercial de las partidas cosechadoras, tractores y sembradoras-abonadoras de Argentina (2008-2014) en millones de dólares corrientes

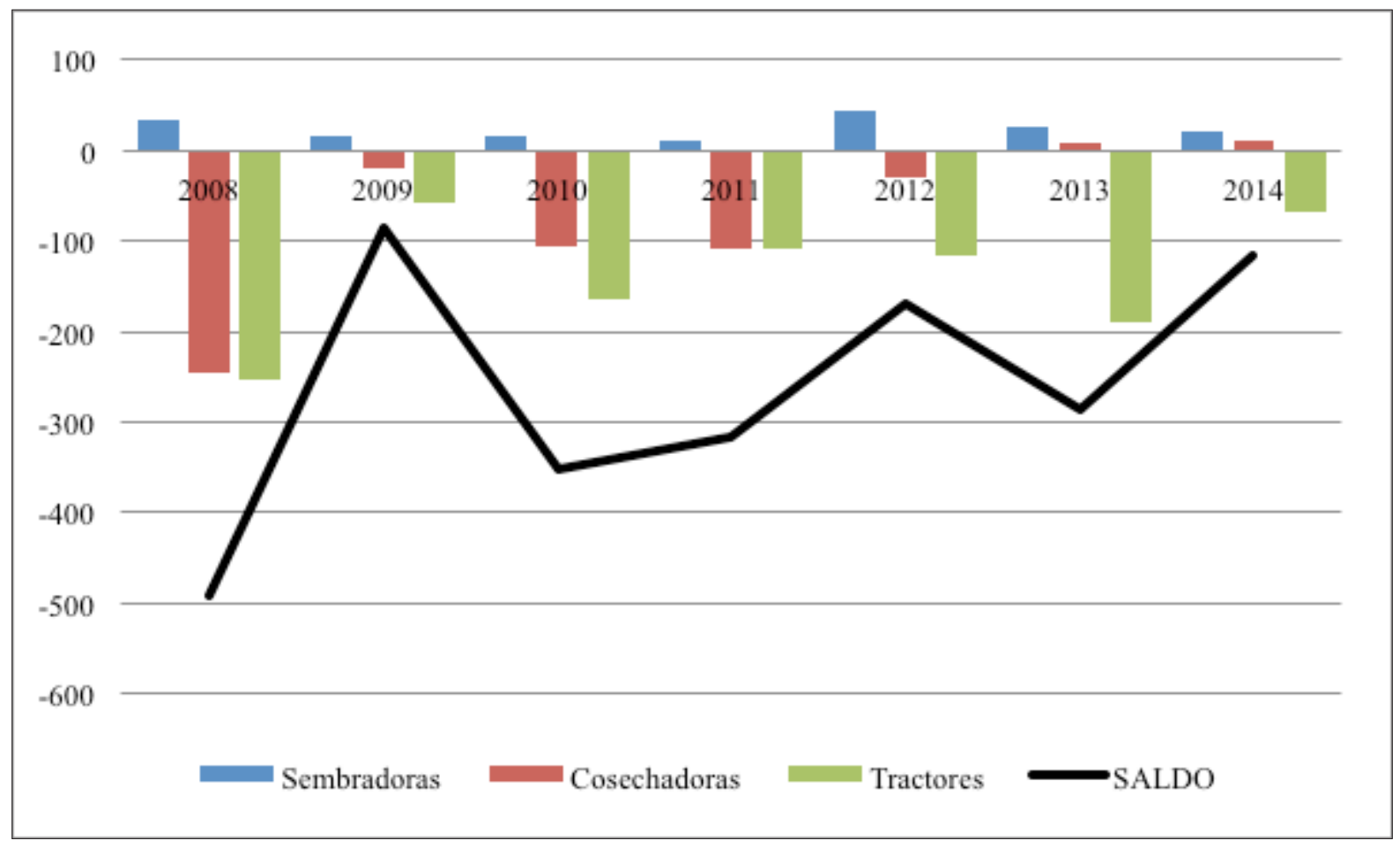

Fuente: elaboración propia con datos de base NOSIS (citado por CAFMA)

En conjunto, no logró alcanzar posiciones de peso en el mercado mundial. En otros trabajos hemos desarrollado nuestra hipótesis, que se resume en la existencia de costos unitarios mayores en la producción argentina, por su reducida escala, que atentaban contra la posibilidad de competir más allá de las fronteras (Bil, 2011). Hoy se replican esos problemas. La producción local no puede competir en mercados externos con productores más eficientes como por ejemplo, a nivel regional, Brasil.

Brasil es uno de los competidores relevantes en América Latina, incluso en el mercado argentino. Por eso el estudio de su performance puede servir como insumo de especial interés para comprender en términos comparativos el peso de Argentina.

\section{La producción en Brasil}

Hasta mediados de los años cincuenta, la industria de maquinaria agrícola en Brasil era reducida. Fue en 1960 cuando se inició la producción de tractores, con Ford y Valmet. Al año siguiente se creó el Grupo Executivo de Industria de Maquinas Agricolas e Rodoviarias, fijándose, al igual que en 1957 en Argentina, cuotas crecientes de integración nacional en los componentes. A partir de la década de 1970 se consolidó como líder en América Latina, por delante de México y Argentina. Lo mismo ocurrió con la industria de cosechadoras. En 1976, se instaló John Deere, adquiriendo el $20 \%$ de la SLC (Schneider \& Logemann), que luego compró en su totalidad. Ese mismo año, la producción llegó a 6.481 unidades. Incluso unos años antes 
los directivos de la cámara empresarial en Argentina percibían la potencialidad de esta industria en el país vecino. En 1969, señalaban que "algunos mercados muy prometedores, como Brasil y México, han desarrollado su propia industria, cerrando así toda esperanza de penetrar con nuestros equipos" (Proyección Rural, 1969).

Desde fines de los setenta, la producción de tractores y cosechadoras experimentó un rápido auge y comenzó a exportar a los países de la región. A partir de 1979 el saldo del rubro fue por primera vez positivo, con veintidós millones de dólares. Desde de ese año, excepto 1999, el saldo fue siempre favorable y en aumento. Consideramos que los motivos que explican el despegue de la actividad en Brasil son: un menor costo laboral y de insumos, y una expansión del mercado interno.

En cuanto al costo laboral, la cámara que reúne a los fabricantes señalaba que entre 1959 y 1973 el salario mínimo real del sector cayó 61\% (ANFAVEA, 2009), mientras que la productividad del trabajo aumentó. Estudios recientes muestran que los costos laborales entre los dos países, en el sector que nos ocupa, continúan siendo más bajo en Brasil, a pesar del deterioro del salario de la clase obrera argentina en las últimas décadas (Cominiello, Morúa et al., 2008). Los salarios reducidos en la siderurgia, incluso por debajo del nivel de Taiwán y Corea en los años ochenta (López y Porta, 1993; Ferraz, Kupfer et al., 2004), permitían lanzar insumos relativamente baratos para los sectores que los consumían, como el de maquinaria agrícola. Cambios productivos en la siderurgia brasileña profundizaron este elemento: durante la segunda mitad de la década del setenta, la producción de acero de Brasil supera los diez millones de toneladas anuales. En 1980 alcanza los quince millones, que le permiten pasar a ser exportador neto. Con cambios productivos y modernizaciones del proceso, entre 1989 y 1998, la productividad de la siderurgia brasileña se duplicó (Cintra, 2007). Estos elementos le permiten a Brasil ser el productor con menores costos en varios rubros de la siderurgia durante las últimas décadas. Por ejemplo, en producción de chapa fría en 1988, el costo de la tonelada en Brasil era apenas un 0,95\% más alto que el del productor más eficiente (República de Corea) y un 12 \% y 23,5 \% más barato que en los Estados Unidos y Japón, respectivamente (López y Porta, 1993). Para 2001, en el conjunto de la producción siderúrgica, tenía una ventaja de costo por tonelada de 7 \% sobre Corea, 42,6\% sobre Japón y 49,2\% sobre Estados Unidos (Cintra, 2007). El precio en el mercado interno brasileño también era menor al de países como EE. UU., Canadá o Japón.

A nivel del mercado, la clave de Brasil es la expansión de la demanda puertas adentro. La concentración del campo brasileño en la producción de cereales alimentó la demanda de equipos (Muller, 1982). También jugó un papel el alto precio del petróleo, que incentivó la búsqueda de energía alternativa. Así nació la propuesta del plan PROALCOOL, para producir combustible por la fermentación de la caña de azúcar. Con eso, aumentó el área sembrada y las demandas para su mecanización. Desde 1975 se dio un proceso de reemplazo del área dedicada a la producción para alimentos por la caña de azúcar y otros destinados al mercado externo (Teixeira, 2005: 28). Entre esos cultivos, se difundió la soja, que demandó "altos factores modernos de producción" (Rezende Gonzalez y Almeida Lima Costa, 1998, 13).

En definitiva, una serie de elementos que aumentaron el mercado interno y la escala aparecieron en Brasil, los cuales no estuvieron presentes en Argentina. El despegue de la producción y el inicio de una corriente exportadora de Brasil con cierta relevancia coincide con 
el momento en el cual los cambios del proceso de producción en la siderurgia permiten que multiplique su producción de acero. Estas condiciones jugaron un papel fundamental para la instalación, hacia finales de los setenta, de los líderes mundiales como plataforma exportadora hacia Sudamérica. Efectivamente, empresas internacionales comenzaron a producir cosechadoras desde mediados de la década mencionada, capitales que nunca habían instalado planta alguna para producir esos equipos en la región. Para esta instalación, algunos señalan las ventajas de Brasil en infraestructura portuaria, logística, y disponibilidad de proveedores (Berlinski, 1993; Hybel, 2006).

Con estas condiciones, en esa década los fabricantes de tractores existentes como Massey Ferguson y otros como John Deere se volcaron también a la producción de cosechadoras, instalando plantas con una capacidad que superaba las necesidades del mercado interno. Es decir, utilizaron al Brasil como una base de exportación al resto del subcontinente, dadas las ventajas que ofrecía en los costos de producción y en transporte e infraestructura.

La recesión de 1981 a 198383, como en otros países, afectó al sector, pero luego la actividad recuperó su ritmo ascendente. Con una regular producción en los años noventa, a partir de la primera década de este siglo aumentó nuevamente. Esto se debió a varios factores, como la devaluación del real, precios agrícolas en alza y créditos accesibles para compra de maquinaria agrícola, instituidos por el programa Moderfrota (Programa para la Modernización de la Flota Agrícola) en 1999. Según los representantes de la cámara brasileña, el plan permitió afrontar una expansión en la capacidad productiva de las fábricas, motivado por la mayor demanda interna.

La década del 2000 experimentó la aparición de nuevas medidas públicas que incentivaron el sector, en particular en el ámbito de la investigación pública. Además, se abrieron nuevas líneas de financiamiento para inversión dispuestas por el gobierno federal (Baricelo, 2015). Con el alza de los precios de los bienes agropecuarios, el mercado interno retomó el vigor de los setenta y aumentó el atractivo para las firmas multinacionales. Según Bekerman y Dalmasso (2014), el Estado brasileño impulsó en la década de 1990 una apertura gradual que protegió a los sectores de contenido tecnológico medio-alto. Asimismo, se asumieron medidas para que la inversión extranjera funcionara de manera virtuosa y otras medidas dirigidas a incrementar la competitividad de su entramado industrial y se estimuló la innovación, continuando medidas que se retrotraen a los años setenta. En los noventa se crearon los "Fondos Sectoriales", para financiar el gasto en I\&D para empresas de distinto carácter. Además, se exigieron mínimos de inversión en desarrollo sobre la facturación anual como condición para acceder a ciertos beneficios impositivos o financieros. Asimismo, durante la última década se mejoró la infraestructura general con programas de desarrollo productivo, modernización industrial, expansión exportadora, promoción sectorial y general, entre otras. En 2003 se implementó en este marco el programa de Política Industrial, Tecnológica y de Comercio Exterior de Brasil (PITCE) y en 2008 se continuó con la Política de Desarrollo Productivo (PDP). Además, se implementaron desgravaciones impositivas para la exportación. Con estas medidas, las multinacionales reforzaron su estrategia de utilizar a Brasil como plataforma para proveer a la región. ${ }^{5}$

5 Este punto habilita un debate que aquí no podemos desarrollar, por falta de espacio, con las corrientes institucionalistas que atribuyen tanto el "éxito" como los límites del desarrollo industrial a la intervención estatal. Si bien es cierto que las políticas públicas facilitaron la expansión de la producción, esta se basó en condiciones estructurales que como explicamos, presentaba Brasil en su economía. Estas condiciones le permiten un 
Entre 2002 y 2014 la producción promedio fue de 64.873 unidades. A pesar de la revaluación del real, que provocó una caída de la producción y de las ventas en 2005 y 2006 por el aumento de los costos de insumos y salarios, en 2013 la producción del sector alcanzó su récord. En contrapartida, las ventas de importados en 2002-2014 solo significaron un 1,5\% del mercado interno brasileño.

Gráfico 9a, 9b y 9c: producción, ventas internas y exportaciones brasileñas de cultivadoras, tractores y cosechadoras (1980-2014) en unidades

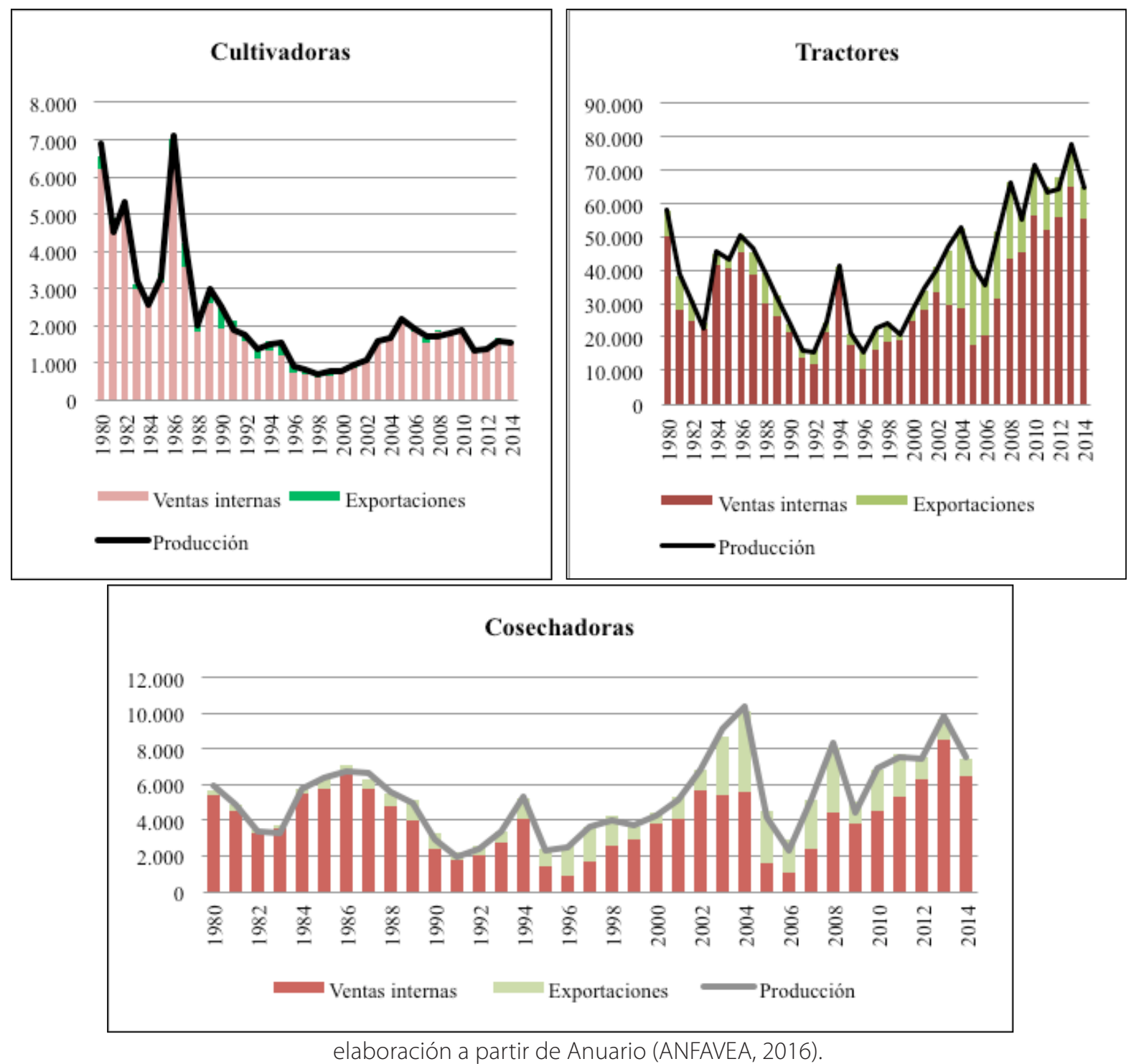

nivel mayor de acumulación de capital en la industria en comparación a la Argentina, pero no convierten al país carioca en una potencia industrial. Evidencia de ello es su matriz exportadora, fuertemente dependiente de commodities agropecuarios y de productos del crudo, y la brusca recesión que experimenta su industria desde 2014. 
Desde mediados de la década de 1990, la producción en Brasil comienza a aumentar de forma más acelerada que las ventas internas. Esto debido a que se destinó una parte a la exportación, que aumentó de forma sostenida. El principal mercado fue Argentina, con $27 \%$ del valor exportado en el periodo, seguido de Paraguay con 10\%, Venezuela con 7,7\% y México y EE. UU. con algo más del $6 \%$ cada uno.

En la relación comercial con Argentina, Brasil exportó entre cosechadoras, tractores y sembradoras por un valor de 1.703 millones de dólares (constantes de 2009). Mientras que Argentina lo hizo por un valor de 3,22 millones. De hecho, en el mercado argentino gran parte de las unidades vendidas durante la última década son brasileñas; por ejemplo, en el primer decenio del siglo XXI entre un $70 \%$ y un $80 \%$ de los tractores y cosechadoras comercializadas provienen del país vecino.

La diferencia está en la productividad del sector en Brasil que, como señalaba un estudio, "en muchos casos multiplican 150 veces la capacidad de venta de un modelo determinado de tractor o cosechadora nacional, dificultando el logro de competitividad [de Argentina] en esos rubros" (Lódola, 2005: 13). En este sentido, las plantas de maquinaria agrícola en Argentina son "pequeñas y con escalas que dificultan alcanzar competitividad internacional en términos de costos y tecnologías". Puede comprenderse en estas condiciones la dificultad de los capitales argentinos para competir no solo en los mercados sudamericanos, sino también en el propio.

No obstante, hay que aclarar que aun en estas condiciones, Brasil no es un exportador de primer orden. En promedio, para el periodo 2002-2011, acaparó un 3,5\% de las ventas mundiales, lo que lo ubicó en el séptimo lugar del ránking internacional. Pero está lejos de los mayores exportadores: representa apenas un $16 \%$ de lo que exporta Alemania (que tiene un quinto del mercado mundial), cuatro veces menos de lo que exporta Estados Unidos (15\% del total mundial), un 37\% de lo que exporta Italia y un 44\% de Japón o Reino Unido.

A pesar de las diferencias de tamaño, los problemas para el sector se han presentado en ambos países. Las dificultades en Brasil, sobre todo como se evidenció en la crisis de 2009 y en menor medida en 2014, y la estructura de la actividad mucho más concentrada que en Argentina, muestran las limitaciones de estos países para consolidarse en el mercado internacional. Estos obstáculos son más graves en el segundo, dado el menor tamaño de sus capitales, que hace al sector más vulnerable a las retracciones en la actividad. Queda pendiente abordar las limitaciones en la escala para futuros trabajos.

\section{Reflexiones finales}

Analizamos la historia de la fabricación de maquinaria agrícola en Argentina en el marco de la competencia internacional. Dados los límites del trabajo, hicimos abstracción deliberada del análisis de otros problemas igualmente importantes para comprender el desarrollo de la actividad. Reseñamos someramente la producción en el país a lo largo de su historia, desde sus orígenes en los últimos años de la década de 1910 (para cosechadoras) y mediados de los años cincuenta (para los tractores). Escogimos estas producciones porque son las de mayor valor agregado y los rubros más importantes del sector. Posteriormente nos dedicamos a analizar el movimiento del mercado mundial en los últimos años, observando tanto los mercados más dinámicos como los exportadores de mayor peso con el agregado del rubro de sembra- 
doras. Consideramos que el elemento de la competencia internacional, en ocasiones omitido por los estudios del sector, nos brinda elementos para acercarnos a la determinación de los niveles de competitividad. En particular, nuestro interés estuvo focalizado en la productividad y condiciones de la actividad en Argentina. El grado de participación en el mercado mundial nos puede mostrar elementos para entender las potencialidades y perspectivas del sector. Hicimos hincapié en este aspecto ya que, sin pretender negar las especificidades regionales, entendemos que la producción y circulación de mercancías es un fenómeno internacional. Al excluir del análisis este condicionante, existe el peligro de caer en la sobrevaluación de las capacidades y perspectivas del sector, como ocurrió para el país mencionado. También existiría el riesgo inverso, es decir, atribuir los déficits a elementos que pierden de vista la competencia internacional, como caer en explicaciones de tipo psicologista ("comportamiento de los actores") o exclusivamente políticas ("faltas de incentivos para el sector"). Al estudiar la competencia internacional, abordamos el estudio del principal competidor del país en la región: Brasil. Por eso, en perspectiva comparativa, analizamos la evolución en los últimos años en Argentina junto a la del país vecino. Encontramos que el primero no llegó a montar una rama con el volumen de producción de los capitales líderes a nivel internacional. Si bien en su momento pudo acaparar la casi totalidad del mercado interno, no logró afianzar sus exportaciones más allá de un corto periodo entre 1960 y 1970, cuando consiguió acceder a mercados secundarios (de Sud y Centroamérica y Africa, principalmente) con cierto volumen. Como hemos trabajado en otros artículos, los problemas principales para lograr economías de escala fueron los altos costos de la fabricación nacional para competir en el mercado mundial, principalmente por el elevado valor de las materias primas, la falta de estandarización de las piezas y los déficits de la industria auxiliar, un mayor costo laboral, dificultades para incrementar la escala e incorporar las técnicas más modernas. Asimismo, durante la década de los setenta se incrementó la producción en Brasil, que desplazó a Argentina de otros mercados y, años después, comenzó a ocupar posiciones en la misma Argentina. Aquí, la crisis internacional de comienzos de los años ochenta golpeó al sector, aunque pudo sostenerse por unos años más. Mantuvo cierto nivel de actividad hasta finales de la década de los noventa, momento en el cual la competencia brasileña, la supresión de aranceles a la importación de bienes de capital y la crisis volvieron a golpear la actividad, sumiéndola en un piso histórico.

Con la devaluación y demanda creciente de equipos por precios internacionales agrarios en alza, durante el siglo XXI la actividad retomó cierto impulso. Las cifras de ese periodo plantearon un panorama de euforia sobre el futuro de la actividad. No obstante, como observamos, los niveles de producción fueron inferiores a los de la "neoliberal" década de 1990. Un análisis más profundo nos permite determinar que el sector no superó sus limitaciones. Es decir, observando la competencia internacional, notamos que la producción en el país se encontraba lejos de disputar posiciones a los productores líderes. En primera instancia, comparamos los niveles de la actividad con Brasil. Notamos una diferencia considerable en los volúmenes de la producción brasileña que dan cuenta de por qué no solo tiene peso en el mercado argentino, sino también en el resto de la región, lo cual la producción argentina no logra.

Con ese dato, analizamos la evolución del mercado mundial. Observamos que aquí la participación argentina es aún menor. Las exportaciones no alcanzaron el 1\% del comercio mundial. La participación es muy reducida en los mercados importadores más dinámicos, como Estados Unidos, Alemania, Francia y Canadá, entre otros. Vale mencionar que Venezuela explica

tiempo\&economía Vol. 4 N. ${ }^{\circ} 1$ - I semestre de 2017 
más del $50 \%$ de las ventas externas argentinas de los últimos años de todo el rubro, principalmente por acuerdos bilaterales entre ambos gobiernos. Cabe señalar que, de todas maneras, el mercado venezolano está acaparado por Brasil, EE. UU. y México.

Históricamente nunca pudo alcanzar la magnitud de producción de los capitales rectores, ni disputarles posiciones en el mercado mundial más allá de ciertas coyunturas aisladas. Hoy día, lejos de haberse reducido esa brecha, se ha ampliado. La producción local no ha podido saltar sobre sus límites históricos y, por ende, sus perspectivas continúan atadas a esa realidad.

\section{Abreviaturas}

ANFAVEA: Associaçao Nacional dos Fabricantes de Veículos Automotores (Rep. Federativa de Brasil)

AFAC: Asociación Fábricas Argentinas de Cosechadoras

AFAT: Asociación Fábricas Argentinas de Tractores

CAFMA: Cámara Argentina de Fabricantes de Maquinaria Agrícola

\section{Referencias}

AACREA (2005). Agroalimentos Argentinos II. Buenos Aires: AACREA.

Albornoz, I., Anlló, G., \& Bisang, R. (2010). La cadena de valor de la maquinaria agrícola argentina: estructura y evolución del sector a la salida de la convertibilidad. Buenos Aires: CEPAL.

Arteche, M., Santucci, M., \& Welsh, S. (2013). Redes y clusters para la innovación y la transferencia del conocimiento. Impacto en el crecimiento regional en Argentina. Estudios Gerenciales 29 (127), 127-138.

Baricelo, L. (2015). A evolucao diferenciada da indústria de máquinas agrícolas: um estudo sobre os casos norte-americano e brasileiro. Mestre em Ciencias. Universidade Sao Paulo.

Baruj, G. (2005). Generación y uso del conocimiento científico. Situación productiva y gestión del cambio técnico en la Industria Argentina de Maquinaria Agrícola. Buenos Aires: Observatorio del Ministerio de Ciencia y Técnica.

Bekerman, M., \& Dalmasso, G. (2014). Políticas productivas y competitividad industrial. El caso de Argentina y Brasil. Revista de Economía Política, 34 (1), 158-180.

Berlinski, J. (1993). Percepción empresarial de los efectos de la apertura unilateral del Mercosur en Argentina y Brasil. Buenos Aires.

Bil, D. (2009). Origen y transformación de la industria de maquinaria agrícola en la Argentina. La trayectoria de Schneider, Istilart y Senor hasta 1940. H-Industria, 4(3), disponible en: http://ojs.econ.uba.ar/ojs/index.php/H-ind/article/view/452

Bil, D. (2011). Acumulación y proceso productivo en la fabricación de maquinaria agrícola en la Argentina (1870-1975). Elementos de su competitividad en el marco del mercado internacional. 
Doctor de la UBA, con mención en Historia. Facultad de Filosofía y Letras, Buenos Aires, Universidad de Buenos Aires.

Bil, D. (2013). El análisis de las exportaciones de maquinaria agrícola argentina como expresión de su competitividad, 1960-1976. Revista Galega de Economía, 22(2), 193-218.

Bil, D., Dachevsky, F., \& Kornblihtt, J. (2010). Debates sobre el desarrollo industrial en Argentina (1930-1976). En E. Sartelli (Dir.), La crisis orgánica de la sociedad Argentina. Buenos Aires: Oficina de Publicaciones de la Facultad de Filosofía y Letras (UBA).

Bragachini, M. (2006). Mecanización agrícola en Argentina. Presente y futuro. Manfredi: INTA.

Cintra, R. (2007). Agendas, atores e lobbies na tomada de decisao em política externa comercial: o caso da siderurgia (Brasil e Estados Unidos). Brasilia: Universidade de Brasilia, Instituto de Relaçoes Internacionais.

Cominiello, S., Morúa, C., \& Mussi, E. (2008). Aproximación a la competitividad de la industria argentina a partir del estudio de los costos laborales (1995-2006). Anuario CEICS, 2, 155-177.

De Cet, M. (2006). The complete encyclopedia of tractors. Amsterdam: Rebo.

García, G. (2005). Régimen de incentivos y conducta tecno-productiva: el caso de tres empresas argentinas de sembradoras, en $X$ Jornadas de Ciencias Económicas y Estadísticas, Universidad Nacional de Rosario.

Gorenstein, S., \& Moltoni, L. (2011). Conocimiento, aprendizaje y proximidad en aglomeraciones industriales periféricas. Estudio de caso sobre la industria de maquinaria agrícola en la Argentina. Investigaciones Regionales 20, 73-92.

Hybel, D. (2006). Cambios en el complejo productivo de maquinarias agrícolas 1992-2004, Documento de trabajo número 3, INTA.

Iñigo Carrera, J. (1998). La acumulación de capital en la Argentina.

looty, M., Kupfer, D. \& Ferraz, J. C. (2004). Competitividad industrial en Brasil. 10 años después de la liberalización. Revista CEPAL, 82, 91-120.

Langard, F. (2014a). Consolidación de cadenas globales de valor y desarrollo de clusters locales: El caso de la maquinaria agrícola en Argentina. Tesis de Doctorado, Departamento de Geografía, UNLP, La Plata, Universidad Nacional de La Plata.

Langard, F. (2014b). Trayectoria de la industria de maquinaria agrícola argentina, entre 1976 y 2002. H-Industria, 8(15), disponible en: http://ojs.econ.uba.ar/ojs/index.php/H-ind/article/ view/732

Lódola, A. (2005). Maquinaria agrícola, estructura agraria y demandantes. La Plata: Universidad Nacional de La Plata.

López, A., \& Porta, F. (1993). Tendencias y factores de competitividad en la industria brasileña. Buenos Aires: CENIT.

Moltoni, L. (2009). Maquinaria agrícola: gestación temprana de una industria pujante, en VI Jornadas de Investigación y Debate "Territorio, Poder e Identidad en el Agro argentino", Universidad Nacional de Quilmes. 
Muller, G. (1982). Agricultura e industrializacao do campo no Brasil. Revista de Economía Política, 2(6), 47-77.

Pellegrini, J. L. (2005). ¿Condenada al éxito? La rama de fabricación de maquinaria agrícola agropecuaria en la Argentina y la evolución reciente de su participación de mercado, en Décimas Jornadas "Investigaciones en la Facultad" de Ciencias Económicas y Estadística, Rosario.

Rezende Gonzalez, B. C., \& Almeida Lima Costa, S. M. (1998). Agricultura brasileira: modernizacao e desempenho, Teoría e Evidencia Económica, 5(10), 7-35.

Sartelli, E. (2006). La Plaza es nuestra. Buenos Aires: Ediciones ryr.

Teixeira, J. C. (2005). Modernizacao da agricultura no Brasil: impactos economicos, sociais e ambientais. Revista Eletrônica da Associação dos Geógrafos Brasileiros, 2(2).

\section{Publicaciones periódicas, regionales o empresarias}

AFAC (1972). La industria argentina de máquinas cosechadoras. Mimeo, archivo Prof. Giberti.

Anuário da Indústria Automobilística Brasileira - 2009 y 2016, ANFAVEA, Sao Paulo.

CAFMA (2016). La Industria de la Maquinaria Agrícola en la Argentina - 2015, en Cámara Argentina de Fabricantes de Maquinaria Agrícola, disponible en: http://www.cafma.org.ar/ cafma/la-industria-de-la-maquinaria-agricola-en-la-argentina-2015/.

Catálogo Cosechadoras Senor. (1940). San Vicente: Senor.

Clarín (2014, 3 de abril). El día que Cristina se subió a la cosechadora que nunca se fabricó, ni vendió. Buenos Aires.

Deere \& Company (2015). Feet on the ground. Eyes on the horizon. Deere \& Company Annual Report 2014. Moline, Illinois: Deere \& Company.

Infobae (2008, 21 de octubre). Maquinaria agrícola: alertan por avalancha brasileña y exigen apoyo.

Infocampo (2008, 13 de noviembre). Maquinaria agrícola: vacaciones hasta febrero para evitar despidos, disponible en: http://www.cafma.org.ar/nota.asp?did=297.

La Nación (2008, 12 de octubre). Fuerte preocupación en las empresas de maquinaria agrícola,

La historia del tractor (1969, octubre). Proyección Rural, 20.

Perspectivas en la exportación (1969, octubre). Proyección Rural, 22.

\section{Informes técnicos o estadísticos del sector}

AFAT: Estadísticas de la industria del tractor (1977-1986); e idem (1982-1991); informaciones estadísticas proporcionadas en la sede de la entidad empresaria.

CAFMA: Maquinaria agrícola - Estimación de la producción nacional en cantidad de unidades (1997-2007), Disponible en: http://www.cafma.org.ar/estadisticas.asp.

Donoso, J. (2007). Situación del sector maquinaria agrícola en América Latina. Rosario: STRAT Consulting. 
Dziecielewski, G. (1973). Export prospects for some sectors of the argentine industry-Agricultural machinery. United Nations Industrial Development Organization.

Estadísticas de productos industriales (EPI): Máquinas de uso agropecuario y sus partes

Fundación Exportar (2008). Plan de Promoción Sectorial - Maquinaria Agrícola. Análisis de Tendencia del mercado internacional - Maquinaria agrícola.

INDEC (2015). Informe de coyuntura de la Industria de Maquinaria Agrícola. Cuarto Trimestre Año 2014. Buenos Aires: Instituto Nacional de Estadísticas y Censos.

INDEC (2016). Estadística de Productos Industriales, en Instituto Nacional de Estadísticas y Censos, disponible en: http://www.indec.gov.ar/nivel4_default.asp?id_tema_1=3\&id_tema_2=6\&id_tema_3=18.

Pérez Ojeda, O. (1970). Informe sectorial sobre la producción de tractores de los países de la ALALC. Buenos Aires: Secretaría de Estado de Industria y Comercio Exterior.

Producción anual desde 1990 en adelante, disponible en: http://www.indec.mecon.gov.ar/ nuevaweb/cuadros/13/EPI-12.xIs. 


\section{Anexo. fuentes y metodología de cálculos}

Utilizamos como fuentes principales diversas series estadísticas elaboradas por organismos oficiales (como las disponibles en el informe sobre maquinaria agrícola que publica el INDEC argentino), información de cámaras empresarias (Cámara Argentina de Fabricantes de Maquinaria Agrícola (CAFMA), Asociación de Fábricas Argentinas de Tractores (AFAT), Associação Nacional dos Fabricantes de Veículos Automotores (ANFAVEA), de organismos supranacionales (la base UNComtrade de Naciones Unidas) y de la base de comercio exterior NOSIS, que reúne información comercial de varios países y partidas arancelarias. También recurrimos a aportes de diversos autores que estudiaron el sector.

Trabajamos las series de la siguiente manera: cuando se trató de reconstruir cantidades, para Argentina empalmamos distintas series desde 1980 a 2014; para Brasil utilizamos directamente la información del Anuario de ANFAVEA. Con la información recogida obtuvimos volúmenes físicos de fabricación y ventas que nos permitieron aproximarnos a la evolución del sector y a una comparación regional.

En las series donde la medida estaba expresada en pesos argentinos (Informe Sector Maquinaria Agrícola, INDEC), deflactamos los valores informados en pesos corrientes por el IPC base 2015 (elaborado a partir de información de INDEC e IPC- provincia de San Luis) para obtener una medida constante comparable para todo el periodo. Esto nos permitió seguir la evolución de la facturación anual en el complejo y determinar picos y pisos de comercialización.

En cuanto a la estadística de comercio mundial de maquinaria agrícola, calculamos a partir de los datos de la base UNComtrade (que recopila información de las oficinas estadísticas gubernamentales de cada país miembro de ONU) la participación anual de cada país en el intercambio y las volcamos en gráficos como promedios para todo el periodo. Las series de cosechadoras y sembradoras llegan hasta el año 2011 debido a que a partir del siguiente año son pocos los países que tienen la información correspondiente de comercio exterior de estas partidas arancelarias en la base. Si bien el precio de los productos en cuestión en el mercado mundial puede sufrir variaciones año a año, consideramos que es el dato obtenido es un indicador muy útil para analizar el flujo mundial de estas maquinarias. 